\author{
Groppo, Bruno
}

Dossier

\title{
Las políticas de la memoria
}

\section{Sociohistórica}

2002, Nro. 11-12, p. 187-198.

Este documento está disponible para su consulta y descarga en Memoria Académica, el repositorio institucional de la Facultad de Humanidades y Ciencias de la Educación de la Universidad Nacional de La Plata, que procura la reunión, el registro, la difusión y la preservación de la producción científico-académica édita e inédita de los miembros de su comunidad académica. Para más información, visite el sitio

\section{www.memoria.fahce.unlp.edu.ar}

Esta iniciativa está a cargo de BIBHUMA, la Biblioteca de la Facultad, que lleva adelante las tareas de gestión y coordinación para la concreción de los objetivos planteados. Para más información, visite el sitio www.bibhuma.fahce.unlp.edu.ar

\section{Cita sugerida}

Groppo, B. (2002) Las políticas de la memoria [en línea].

Sociohistórica, (11-12). Disponible en:

http://www.fuentesmemoria.fahce.unlp.edu.ar/art_revistas/pr.3067/pr. 3067.pdf

\section{Licenciamiento}

Esta obra está bajo una licencia Atribución-No comercial-Sin obras derivadas 2.5 Argentina de Creative Commons.

Para ver una copia breve de esta licencia, visite http://creativecommons.org/licenses/by-nc-nd/2.5/ar/.

Para ver la licencia completa en código legal, visite http://creativecommons.org/licenses/by-nc-nd/2.5/ar/legalcode.

O envíe una carta a Creative Commons, 559 Nathan Abbott Way, Stanford, California 94305, USA. 


\section{Las políticas de la memoria}

\section{- Bruno Groppo}

El tema de la memoria ha adquirido en el curso de las últimas décadas una importancia cada vez mayor en muchos países, en particular en Europa y, más ampliamente, en la cultura occidental. La multiplicación de las publicaciones, el eco que encuentra en los medios de comunicación, los debates que suscita son algunos de los síntomas de este interés creciente. La atención está dirigida a la memoria de acontecimientos traumáticos (guerras, dictaduras, masacres): desde este punto de vista, la memoria de la Shoah se ha convertido en paradigma. El interés por la memoria se incrementó también en Argentina, como lo muestran este coloquio y otras iniciativas que vieron la luz en los últimos años. Esta coyuntura general favorable para una reflexión sobre la memoria tiene varias causas que no pueden ser analizadas hoy, aquí, de manera profunda. Por eso, me limitaré a señalar una que merece, en mi opinión, una atención particular y es, justamente, el hecho de que un determinado número de identidades colectivas, que antes parecían sólidamente arraigadas, han devenido más inciertas y se ven amenazadas por un proceso de cambio que se acelera sin cesar y frente al cual, por sus dimensiones planetarias, nos sentimos a menudo impotentes. En este contexto, la memoria es percibida como un punto de anclaje y como una garantía para las iden-

Universidad de París I - CNRS (Centro Nacional de Investigación Científica) - Centro de Historia Social del Siglo XX 
tidades amenazadas. En efecto, existe una relación estrecha entre memoria e identidad y es sobre este punto y, más específicamente sobre las políticas de la memoria, que propongo, a continuación, algunos elementos de reflexión.

Cada sociedad vive a su manera, en función de su historia y de sus problemas específicos, la coyuntura de memoria que acabamos de evocar. En el caso de la Argentina, es sobre todo la memoria dolorosa de la última dictadura y de sus crímenes la que se encuentra en el centro de atención. En efecto, a pesar de los intentos del poder político por imponer el olvido (en particular por las leyes de amnistía conocidas bajo el nombre de "Punto final" y "Obediencia debida") y del deseo de una parte de la sociedad de dar vuelta la página definitivamente, el olvido se reveló imposible. Este pasado no quiere morir -retomo acá la fórmula utilizada por Ernst Nolte a propósito del pasado nazi en Alemania-y sigue, entonces, atormentando al presente. Las razones son bien conocidas y bastará aquí recordarlas sumariamente: la naturaleza de los crímenes cometidos por la dictadura, que los hace imprescriptibles (ya que se trata de crímenes contra la humanidad); el problema, no resuelto, de decenas de miles de desaparecidos, de quienes ignoramos las circunstancias de su muerte; el problema, tampoco resuelto, de cientos de hijos de desaparecidos, niños en ese entonces, que las fuerzas de represión se apropiaron y que no fueron restituidos a sus familias naturales; el carácter inaceptable de la impunidad garantizada a los criminales por las leyes de amnistía; la acción de numerosas asociaciones de derechos del hombre y de familiares de las víctimas que continúan reclamando verdad y justicia; la acción de la justicia penal internacional.

Por otra parte, en la coyuntura actual, marcada por una crisis económica y social sin precedentes, es imposible olvidar que los fundamentos del modelo económico y social que condenó a la pobreza a la mitad de la población fueron establecidos, precisamente, en la época de la dictadura militar. El neoliberalismo salvaje, la desindustrialización, la especulación financiera desenfrenada, el desmantelamiento del sistema de protección social, el abandono de las funciones reguladoras del Estado, la explosión de la deuda externa nos conducen a las transformaciones estructurales impuestas por la dictadura. Entonces, el problema no es sólo el de los crímenes que permanecen impunes, sino también, más en general, el de la herencia estructural dejada por la dictadura, de la que se hicieron cargo los diferentes gobiernos que se sucedieron después. El recurso a la memoria no es, entonces, un lujo inútil o una operación masoquista destinada a prolongar indefinidamente el sufrimiento, sino, por el contrario, la condición indispensable para intentar comprender el desastre actual y para orientarse hacia un futuro menos calamitoso. Ésta es la razón por la cual constituye una cuestión 


\section{Las políticas de la memoria}

que concierne no sólo a aquéllos que sufrieron más directamente la dictadura, sino al conjunto de la sociedad.

Casi un cuarto de siglo nos separa del fin de la dictadura. Es decir, que la parte más joven de la población no vivió esta experiencia y sólo la conoce indirectamente, a través de las conversaciones en familia, los medios de comunicación, las lecturas, la escuela. Los monumentos que recuerdan esta época no son muchos. La mayoría de los lugares de memoria ligados al terrorismo de Estado y a su política de exterminio han desaparecido. Las conmemoraciones oficiales son raras o inexistentes. Las familias de las víctimas, las Madres y Abuelas de la Plaza de Mayo, los HIJOS, las asociaciones de derechos humanos mantienen viva la memoria de esta época trágica, pero, probablemente, una parte de los jóvenes ignoren el nombre de Astiz o Massera o lo que ocurría dentro de la ESMA (Escuela de Mecánica de la Armada). El problema de la memoria se plantea, entonces, cada vez más como un problema de transmisión en dirección de las nuevas generaciones que no conocieron la época del sedicente "Proceso". Surgen, entonces, múltiples cuestiones. ¿Qué debemos transmitir? ¿Cómo hay que recordar ese pasado? ¿Qué aspectos hay que retener? ¿Qué significaciones puede tener hoy una política de la memoria que pretenda confrontarse con ese pasado? ¿Qué obstáculos debe esperar? ¿En qué medida la sociedad puede reconocerse en una memoria común? ¿Hay memorias más legítimas que otras? ¿Por qué recordar? Estaríamos tentados de responder: porque no podemos no hacerlo, ya que, en cierta forma, no es una elección sino un dato insoslayable. Hemos visto que muchos problemas permanecen abiertos, sin solución y no podemos hacer como que los ignoramos. Pero podemos proponer también otra respuesta, a mis ojos más pertinente. Es la siguiente: en una historia no obstante rica en violencia como la de la Argentina, el terrorismo de Estado de la última dictadura constituyó una experiencia extrema (un poco como, en una más amplia escala, lo fue la Shoah o el Gulag soviético). La conciencia de haber consumado un salto cualitativo en el horror, de haber franqueado un límite, permanece presente en la sociedad y se acompaña de la idea de que semejante experiencia, por el sólo hecho de haberse producido una vez, podría repetirse. Transmitir la memoria tiene, entonces, también, la función de exorcizar una posible repetición.'

\footnotetext{
1 Desde este punto de vista, muchas de las reflexiones desarrolladas por Primo Levi (en particular en su libro Los hundidos y los salvados, Barcelona, Muchnik Editores, 2000) a propósito de la Shoah podrían aplicarse también al caso argentino.
} 


\section{Memoria e identidad}

La cuestión central que nosotros queremos explorar es la del lazo entre memoria e identidad. La memoria es, se sabe, el principal fundamento de la identidad, tanto individual como colectiva. Ella es, en efecto, quien, "nos dice por qué somos lo que somos", para retomar la expresión de Umberto Eco. ${ }^{2}$ Perder la memoria equivale a perder la identidad. "Sin memoria, una persona no se reconoce más, se desintegra y deja, por ese mismo hecho, de existir", escribe el historiador polaco Krysztof Pomian. ${ }^{3}$ Esta observación puede aplicarse, igualmente, a los grupos sociales y a las identidades colectivas. La identidad de un grupo social, en efecto, es indisociable de su memoria, porque es precisamente por intermedio de esta última que la identidad se construye y se transmite. La identidad no es una esencia inmutable, determinada de una vez y para siempre, que se trasmite idéntica de una generación a otra, sino una construcción social y cultural; dicho de otro modo, el producto de un proceso histórico que se apoya sobre la memoria y que, como la memoria, funciona dentro de ciertos marcos sociales. El trabajo ininterrumpido de la memoria modifica continuamente la identidad: "ninguna forma de identidad se conserva indefinidamente en el tiempo sin transformarse". ${ }^{4}$ En tanto construcción cultural, presenta aspectos estables -un núcleo central que persiste en el tiempo-y aspectos mutables: "ella se presta a ser reconstruida continuamente, al menos en cierta medida, según el contexto y las oportunidades". Cuando hablamos de memoria, también hablamos de identidad. A nivel social, a través de un cierto tipo de memoria, es decir de relación selectiva con el pasado, se dibuja un cierto tipo de identidad colectiva. Transmitiendo e intentando hacer prevalecer una cierta identidad del pasado, las políticas de la memoria se esfuerzan precisamente por forjar una identidad colectiva, en particular una identidad nacional que corresponda al tipo de sociedad que ellas consideran deseable. En la medida en que estas políticas busquen orientar la evolución de la sociedad, son verdaderas políticas, del mismo rango, por ejemplo, que las políticas económicas, y juegan un papel importante que haríamos mal en subestimar.

En toda sociedad existe una pluralidad de memorias colectivas y, por lo tanto, de identidades colectivas: hay tantas memorias sociales como grupos sociales.

\footnotetext{
${ }^{2}$ Umberto Eco, (1999) "Preámbule", en: ¿Pourquoi se souvenir?, bajo la dirección de Françoise BarretDucrocq, Paris, Grasset, p. 239.

${ }^{3}$ Krzysztof Pomian, (1999) Sur l'histoire, Paris, Gallimard p. 271.

${ }^{4}$ Remo Bodei, (1995) Libro della memoria e della speranza, Bologna, II Mulino, p. 27.

${ }^{5}$ Maurizio Bettini, (2001) "Sul perdono storico. Dono, identità, memoria e oblio", en Marcello Flores (dir.), Storia, verità, giustizia. I crimini del XX secolo, Milano, Bruno Mondadori, p. 31.
} 
Pueden distinguirse memorias/identidades fundadas en la pertenencia familiar, profesional, sexual, política, religiosa, generacional, etc. Cada individuo se sitúa en el cruce de varias memorias/identidades, ya que pertenece, a la vez, a varios grupos (familia, generación, sexo, profesión, etc.), cada uno con una memoria y una identidad propias. Una memoria común es, a veces, el único fundamento de un grupo: en el caso de ex combatientes, por ejemplo, es el recuerdo de una experiencia vivida en común, la guerra, lo que constituye el "cemento" del grupo.

Las diferentes memorias colectivas que coexisten en el seno de una sociedad compiten, a menudo, y a veces también están en conflicto directo y abierto unas con otras, ya que ellas comunican vivencias y representaciones del pasado que pueden ser completamente opuestas. Para permanecer en el ejemplo argentino, la memoria de las víctimas y la de los responsables de la dictadura son evidentemente antagónicas: conciernen a un mismo pasado, que sin embargo fue vivido de una manera diferente por estos dos grupos. La memoria, en efecto, es la presencia viva del pasado, la huella de una vivencia que se mantiene en las personas que tuvieron la experiencia directa, o en aquéllas a quienes la vivencia les ha sido trasmitida. ${ }^{6}$ En consecuencia, se asiste a verdaderas batallas de memoria cuya apuesta es la conquista de la memoria pública, es decir, de la memoria del mayor número, ésa que cada una de las memorias presentes y en lucha querría modelar a su propia imagen, imponiendo sus recuerdos al conjunto de la colectividad. Podemos distinguir, desde este punto de vista, dos tipos de memoria: por un lado, las memorias sociales estructuradas, como las memorias de grupo, la memoria oficial (la que el gobierno, el régimen o el grupo en el poder quiere imponer) y la memoria erudita (la construida por los historiadores); por otro lado, una memoria no estructurada, la memoria pública, que es la memoria clave a la que todas las otras se esfuerzan por influenciar. ${ }^{7}$

Presencia viva y activa del pasado, la memoria colectiva, lejos de quedar fijada, se modifica continuamente. Maurice Halbwachs ya subrayaba que "el recuerdo es, en muy amplia medida, una reconstrucción del pasado con ayuda de datos tomados del presente", ${ }^{8}$ y que, por consiguiente, la memoria jamás es

\footnotetext{
${ }^{6}$ Retomo aquí los conceptos de Henry Rousso, quien escribe: "La memoria, sea individual o colectiva, designa la presencia del pasado, una presencia viva, activa, transmitida por sujetos $\mathrm{y}$, por tanto, por una palabra y no simplemente por huellas materiales [...] la memoria no es todo el pasado: la parte que continúa viviendo en nosotros es siempre tributaria de las representaciones y de las preocupaciones del presente. Pero ella es todo lo que del pasado continúa viviendo en nosotros, por el fruto de la experiencia directa, vivida o de una transmisión familiar, social o política" (Rousso, Henry, "Le statut de l'oubli", in Pourquoi se souvenir?, op. cit., p. 109).

7 Retomo aquí por mi cuenta las distinciones que propone Frank Robert, "La place des deux guerres mondiales dans les manuels scolaires français", La Nouvelle Alternative, no 37, marzo 1995, pp. 7-9.

${ }^{8}$ Halbwachs Maurice, (1997) La mémoire collective, Paris, Albin Michel, pp. 118-119.
} 
una restitución idéntica del pasado, sino una reconstrucción continuamente recomenzada del pasado, en función del presente. Incluso la memoria erudita, la de los historiadores, reinterpreta sin cesar el pasado, a la luz del presente: los acontecimientos a los que se refiere pueden ser los mismos, lo que cambia es la interpretación que ha sido dada. Muy a menudo, en efecto, lo que constituye un problema no es tanto los hechos, sino el significado que se les atribuye.

Se subraya siempre el carácter selectivo de la memoria que sólo retiene algunos elementos del pasado, mientras condena a otros al olvido. La selectividad es constitutiva de la memoria por la simple razón que no podemos acordarnos de todo. En este sentido, memoria y olvido son las dos caras de una misma medalla y, por tanto, indisociables. Como lo observa Henry Rousso, "recordar es siempre, más o menos, olvidar algo, ya que es desplazar la mirada retrospectiva y recomponer, de este modo, otro paisaje del pasado". ' Cada memoria sólo restituye una parte o un fragmento del pasado. Por esto, ninguna memoria puede pretender la exclusividad, aun cuando algunas memorias, por ejemplo, la de las víctimas que se ha intentado deliberadamente borrar o ahogar, merecen, por este sólo hecho, una atención particular.

\section{Políticas de la memoria}

Una política de la memoria es una acción deliberada, establecida por los gobiernos o por otros actores políticos o sociales con el objetivo de conservar, transmitir y valorizar el recuerdo de determinados aspectos del pasado considerados particularmente significativos o importantes. Por la representación que propone del pasado, ésta apunta, como ya lo hemos indicado, a modelar la memoria pública y a construir, así, un cierto tipo de identidad colectiva. Utiliza el pasado reconstruyéndolo en función de los problemas y las preocupaciones del presente; aunque trabaja sobre el pasado, está vuelta hacia el futuro ya que ella dibuja implícitamente un cierto tipo de sociedad. Según los objetivos perseguidos, existen políticas de la memoria muy diferentes, algunas de las cuales se inscriben en una lógica democrática mientras que otras, por el contrario, responden a una lógica autoritaria. En sí, en efecto, la memoria no es ni buena ni mala: todo depende del uso que se haga de ella. ${ }^{10}$ Son numerosos los ejemplos de un mal uso de la memoria. Entre

"Rousso, H, art. cit., p. 111. Rousso observa también que "a memoria es un proceso complejo que articula recuerdos y olvidos, lo consciente y lo inconsciente, la parte aceptada y asumida del pasado como su parte negada y oculta" (Idem., p. 109).

10 Cf. Todorov, Tzvetan, (1995) Les abus de la mémoire, Paris, Arléa, 1995. 
los más recientes, podemos citar, entre otros, el de la utilización por el nacionalısmo serbio de ciertas memorias (próximas, como la de Kosovo o, más lejanas, como las concernientes a la Segunda Guerra Mundial), artificialmente reavivadas con el fin de legitimar el proyecto expansionista de la Gran Serbia y las masacres que provocó. De manera general, todos los regímenes dictatoriales intentan legitimarse manipulando la memoria y apelando a un pasado más o menos mítico. Es necesario, entonces, reflexionar sobre el uso que se hace de la memoria ya que, en ciertos casos, puede ser absolutamente destructivo. Lo mismo ocurre con el olvido que puede tener tanto una función terapéutica como efectos patológicos. Ya en 1882 Ernest Renan, en una célebre conferencia en la Sorbona, subrayaba la importancia del olvido, junto a la memoria, en la construcción de las naciones modernas." Puede afirmarse que las identidades colectivas se fundan, a la vez, sobre una memoria común y sobre olvidos compartidos. En ese sentido, el olvido es también constitutivo de esa identidad colectiva que es la memoria. Lejos de ser necesariamente un fenómeno negativo, una ausencia lamentable, "puede ser considerado también como una ventaja que permita a la persona o a un grupo construir o restaurar una imagen de sí, globalmente satisfactoria". ${ }^{12}$

Una política de la memoria puede presentar muy diversas formas: conmemoraciones y rituales, construcción de monumentos, preservación de determinados "lugares de memoria", creación de instituciones encargadas de la conservación y transmisión de la memoria (archivos, museos, centros de documentación, institutos de investigación), programas escolares, toponimia, etc. Cualquiera sea el método elegido, ella selecciona determinados aspectos del pasado, les atribuye un sentido particular y define, de este modo, el contenido y los límites de la memoria social deseada.

Seleccionar, quiere decir preservar determinados elementos del pasado y eliminar otros considerados menos significativos. Es porque toda política de la memoria es también, al mismo tiempo e inevitablemente, una política del olvido, ya que, al decidir prestar atención a ciertos aspectos del pasado, ella deja otros en la sombra -deliberadamente o no. Pero también existen auténticas políticas del olvido que podríamos definir activas y "que tienen por objeto declarado, explícito, eliminar determinados acontecimientos de la memoria colectiva". ${ }^{13}$ Es el caso, principalmente, de la amnistía que es una forma de olvido político y jurídico que apunta a imponer una amnesia social. Se trata naturalmente, como lo remarca

\footnotetext{
11 "La esencia de una nación es que todos los individuos tengan muchas cosas en común y, también, que todos hayan olvidado unas cuantas cosas" (Renan, Ernest, (1992) Qu'est-ce qu'une nation ?, Paris, Presses Pocket, p. 49).

${ }^{12}$ Candau, Joël, (1996) Anthropologie de la mémoire, Paris, PUF, p. 83.

${ }^{13}$ Rousso, ob. cit., p. 111.
} 
Rousso, de un olvido relativo, puesto que los acontecimientos en tanto tales no son olvidados, pero ya no pueden ser evocados públicamente. La amnistía representa una forma extrema de política del olvido. También se puede tratar de obtener el mismo resultado por otros medios: evitando, por ejemplo, evocar determinados acontecimientos eliminándolos de los programas escolares, destruyendo las huellas materiales (edificios, documentos) del pasado que se pretende borrar y evitando que queden signos visibles que lo recuerden. Se sabe, por ejemplo, que una de las últimas disposiciones tomadas por la dictadura militar argentina antes de dejar el poder fue la orden de destruir todos los documentos concernientes a la represión ilegal. De la misma manera, ésta se ocupó de borrar las huellas de innumerables centros de detención clandestina y de tortura que habían proliferado en el país. El proyecto del ex presidente Menem de liquidar el inmueble de la tristemente célebre ESMA, uno de los más importantes de estos centros de detención, es también un ejemplo notable de política de olvido. Al respecto, hay que observar que la destrucción de los lugares de memoria es una manera particularmente eficaz de imponer olvido porque la memoria, para conservarse y trasmitirse, necesita marcas materiales a las que poder aferrarse. En Europa, la memoria de los crímenes del nazismo sería indudablemente menos fuerte si no quedase ninguna huella de los campos de concentración y de exterminio construidos por el régimen de Hitler. Es sobre todo a nivel de la transmisión de la memoria que las políticas del olvido pueden ser eficaces. Quienes han sido testigos de determinados acontecimientos difícilmente los olvidarán pero para aquellos que no los han vivido personalmente estos acontecimientos no habrían existido si la memoria no hubiese sido trasmitida. Es el problema que se plantea siempre con las nuevas generaciones: de allí la importancia de la transmisión oral, en el seno de la familia o de grupos sociales más amplios, junto a una transmisión más institucional que se efectúa por la vía escolar, las conmemoraciones, los monumentos, la atribución de nombres de calles. La importancia de los medios de comunicación en la transmisión de la memoria no tiene necesidad de ser subrayada. Es en gran parte por su intermedio que se impone una cierta representación del pasado.

\section{¿Qué políticas de la memoria en la Argentina actual?}

Luego de estas consideraciones generales, nos preguntamos ahora qué significado puede tener, en la Argentina actual, una política de la memoria que quiera inscribirse en el marco de la democracia y cuáles son las tensiones que 
deberá tener en cuenta. La significación de semejante política depende, sobre todo, de dos elementos: por un lado, de los objetivos que le asignen las personas o las instituciones que tomen la iniciativa de llevarla adelante y que la pongan en marcha (dicho de otro modo, del uso público que se pretenda hacer del pasado); por otro lado, del eco que esta política encuentre en la sociedad.

Si nos situamos en una perspectiva democrática, como es el caso de casi todos aquellos que, en Argentina, se interesan por los problemas de la memoria, un objetivo esencial es permitir a la sociedad no sólo conocer su pasado hasta en sus aspectos más dolorosos, sino también y sobre todo de asumirlo, es decir, de reconocerlo como propio: tal es, en efecto, la condición indispensable para que una sociedad pueda superar los traumatismos del pasado y procurar que éste se convierta efectivamente en pasado. Es así como una política de la memoria que apunte a conocer y a dar a conocer la verdad histórica puede convertirse en un instrumento importante de democratización de la sociedad. En la situación actual, este objetivo es difícil de alcanzar porque, sin duda alguna, una parte de la sociedad no está siempre dispuesta a aceptarlo y, más aún, porque este ejercicio de verdad sería incompatible con el mantenimiento de la impunidad garantizada a los responsables de los crímenes contra la humanidad cometidos durante la dictadura. La impunidad es, en efecto, un obstáculo mayor que bloquea el proceso de confrontación con el pasado. Su mantenimiento prueba, por otra parte, que las fuerzas hostiles a este proceso de rememoración conservan una gran influencia y un poder de veto. La salida de la crisis que atraviesa actualmente el país influirá, además, sobre las posibilidades de una política democrática de la memoria. Estas oportunidades serán más grandes si la crisis condujese al reemplazo de una gran parte de la actual clase política, corrupta y desacreditada, que no tiene interés alguno en echar luz sobre el período de la dictadura porque ella ha sido, en gran medida, cómplice. Estas probabilidades serán muy reducidas, si la salida de la crisis conllevase el refuerzo de las élites políticas y económicas actuales. Hoy, parece poco probable que una política de la memoria que se refiera al período de la dictadura pueda instalarse a nivel nacional; de allí, la importancia de las iniciativas que se desarrollan, en este terreno, a nivel provincial y local.

Inmediatamente hay que interrogarse sobre el contenido de una política de la memoria y preguntarse qué aspectos del pasado se quieren privilegiar. Se escucha seguido hablar de "construcción de la memoria colectiva". Esta fórmula, en sí, no dice gran cosa ya que el problema, en realidad, es el de saber qué memoria queremos construir y transmitir. La respuesta depende de la interpretación que se proponga de ese pasado ya que es ella quien proporciona los criterios para distin- 
guir lo que es significativo de aquello que lo es menos. Ahora bien, cualquier interpretación implica un cierto grado de subjetividad y este factor nunca puede ser totalmente eliminado. Lo que puede hacerse, en cambio, es explicitar los criterios que guían una cierta interpretación del pasado y, entonces, una determinada política de la memoria. En el plano del método, es indispensable tener en cuenta la pluralidad de las memorias involucradas en este período de la historia argentina y reconocer que ninguna memoria particular puede pretender ocupar totalmente el terreno, excluyendo a todas las otras. Una política de la memoria que desee acercarse lo más posible a la verdad histórica no puede ni debe pretender ningún monopolio sino que debe esforzarse, por el contrario, para tener en cuenta la pluralidad y la diversidad de las memorias existentes. Cada memoria, en efecto, hace circular una visión particular del pasado. Penetrado por memorias diferentes, un mismo pasado se presenta bajo formas diversas porque, como ya lo hemos subrayado en varias ocasiones, cada memoria sólo selecciona y retiene determinados aspectos, testigos de una vivencia específica con exclusión de otras. Lo que es significativo para una memoria no lo es necesariamente para otra. A esto se agrega el hecho que cada memoria social constituye un conjunto complejo, compuesto de sub-memorias diferentes, ellas mismas en perpetua recomposición. Toda construcción del pasado propuesta por una política de la memoria debe tener en cuenta esta complejidad, pluralidad y mutabilidad de la memoria, evitando la tentación de proponer una interpretación que pretenda ser definitiva, fija, de una vez y para siempre. Ella debe admitir que no es la única posible y que la mirada lanzada sobre el pasado cambia continuamente en función de las preocupaciones del presente. Se trate de la memoria pública (la del mayor número) o de la memoria erudita (la de los historiadores), el cambio es la ley del género. Cada interpretación está inevitablemente "fechada" y destinada a ser revisitada por interpretaciones ulteriores. Importa, en cambio, que las interpretaciones futuras puedan apoyarse sobre una base documental vasta y diferenciada que se trata de conservar (hasta de constituir, como en el caso de testimonios orales que puedan recogerse) y transmitir. Éste es un punto esencial. Crear, preservar, poner a disposición una base documental tiene un interés común para todos aquellos (asociaciones, instituciones, grupos) que se sienten involucrados en la memoria de la dictadura. Sólo podemos acercarnos a la verdad histórica de este período trágico sobre la base de documentos. No obstante, sería ingenuo e ilusorio creer que los documentos entregan automáticamente la verdad histórica: sólo "hablan", en realidad, en función de las preguntas que les hagamos y exigen, por tanto, la intervención del historiador. En el caso de Argentina, la preservación de docu- 
mentos constituye una prioridad absoluta. Las lagunas existentes son enormes, en particular para todo lo que se refiere a la represión, ya que la dictadura se esforzó en destruir sistemáticamente este tipo de documentos. Sabemos, no obstante, que teniendo en cuenta la complejidad de los sistemas burocráticos modernos, es prácticamente imposible de destruir completamente. Probablemente se descubrirán numerosas huellas en diferentes archivos nacionales o locales, por ahora todavía inaccesibles. Por otra parte, iniciativas como los "juicios de la verdad" permiten reunir nuevos testimonios y nuevos documentos. Debido a la coordinación internacional de la represión entre las dictaduras militares del Cono Sur y de los países limítrofes, igualmente figuran en los archivos de otros países los documentos referidos a la represión en Argentina. El descubrimiento reciente, en Paraguay, de archivos vinculados a la "Operación Cóndor" es un buen ejemplo de esto. Además, los archivos de empresas, en la medida en que se hayan conservado, pueden proporcionar elementos preciosos de información sobre la represión contra los militantes obreros y sindicales, mientras que los archivos de la Iglesia católica y otras confesiones religiosas contienen, indudablemente, numerosos documentos sobre las víctimas de la represión, la solidaridad respecto de ellas y, también, sin duda, sobre la complicidad de una parte de la jerarquía católica con la dictadura.

Como vemos, la base documental posible es inmensa. Poner el acento sobre este punto significa desplazar el acento de la memoria, en tanto presencia viva del pasado, a la historia. Sólo sobre el terreno de la historia, en mi opinión, se puede construir una memoria común, respetuosa de la diversidad de las memorias sociales existentes pero preocupada, ante todo, de aproximarse a la verdad histórica. Esto significa que una política de la memoria, para tener una base sólida, debe apoyarse en el trabajo de los historiadores, en particular en todo lo que concierne la recolección, la conservación, el catálogo y la interpretación de los documentos. Ahora bien, los caminos del historiador y de las asociaciones militantes que se ocupan de la transmisión de la memoria no son necesariamente los mismos. Se trata, entonces, de encontrar un terreno de entendimiento que permita respetar, a la vez, las reglas del oficio de historiador y la especificidad de las memorias militantes. Este trabajo, esencial, en gran parte está por hacerse. Constituye, en mi opinión, una prioridad urgente.

Las memorias de los diferentes grupos sociales contienen todas una parte de la verdad $y$, desde este punto de vista, son todas legítimas. No obstante, no pueden reemplazar a la historia en tanto intento de reconstrucción e interpretación del pasado sobre la base de criterios científicos y con el objetivo de llegar lo más rápido posible a la verdad. En cuanto a la historia, que también es una forma de 
memoria (una memoria erudita), debe abrevar en las múltiples memorias sociales e integrarlas a su discurso, utilizándolas como elementos indispensables, junto a otras, para la reconstrucción del pasado. Por eso, es importante, por ejemplo, formar especialistas que sepan abordar los problemas de la memoria a partir de una sólida formación histórica, como se propone hacerlo esta Universidad. Saludamos las diferentes iniciativas que en este sentido se desarrollan en el país sobre dichas perspectivas. Hay que desear que se establezca, además, una cierta coordinación entre ellas.

Ya hemos señalado que una política de la memoria apunta esencialmente a construir y a transmitir una identidad. Ahora bien, como lo subraya Maurizio Bettini, el verdadero problema no es el de la memoria y el olvido en tanto tales -ya que "considerados en sí mismos, pueden producir tanto el bien como el mal'- sino más bien el de su relación con la identidad. A nivel de una sociedad considerada en su conjunto, se trata de saber en qué identidad colectiva puede o quiere ésta reconocerse.

"Ese lazo entre memoria colectiva, olvido e identidad no se establece sólo en los momentos de crisis reciente [...], sino que se vuelve a proponer cada vez que es necesario afirmar 'quienes somos': cuando, por una razón u otra, el grupo al que se pertenece utiliza la memoria del pasado o su olvido, para identificarse. [...] El desafío cotidiano de la coexistencia entre los grupos se reduce, en definitiva, a la buena utilización de la relación que estos grupos establecen entre la memoria y el olvido, cuando se trata de construir su memoria colectiva y, con esta última, su identidad. Habrá que decidir cada vez lo que conviene recordar y lo que es oportuno olvidar, cuáles conexiones identitarias es mejor reactivar o dejar caer en el olvido". ${ }^{14}$

Este problema me parece particularmente agudo en este momento de crisis, muy grave, que se vive en Argentina: una crisis que no es sólo económica, social y política, sino también de identidad. En el momento actual, sería difícil afirmar en qué se funda hoy, en Argentina, el sentimiento de una pertenencia y de un destino comunes. ¿Cuáles "conexiones identitarias" serán reactivadas? ¿A qué tipo de memoria apelaremos para reconstruir una identidad en crisis? Estas preguntas siguen quedando abiertas. La relación con el pasado siempre ha sido compleja y contradictoria en la Argentina del siglo XX: $:^{15}$ hoy, lo es aún más.

Traducción: Ana M. Barletta

\footnotetext{
${ }^{14}$ Bettini, op. cit., pp. 42-43.

${ }^{15}$ Cfr. sobre este punto, el notable trabajo de Diana Quattrocchi-Woisson, (1998) Los males de la memoria. Historia y política en la Argentina, Buenos Aires, Emecé Editores.
} 